\title{
CRIANÇA HOSPITALIZADA: PERCEPÇÃO DAS MÃES SOBRE O VÍNCULO AFETIVO CRIANÇA-FAMÍLIA*
}

Beatriz Rosana Gonçalves de Oliveira**

Neusa Collet***

OLIVEIRA, B.R.G.de; COLLET, N. Criança hospitalizada: percepção das mães sobre o vínculo afetivo criançafamília. Rev.latino-am.enfermagem. Ribeirão Preto, v. 7, n. 5, p. 95-102, dezembro 1999.

Este trabalho objetivou verificar a percepção da mãe que tem seu filho doente hospitalizado, sobre a importância de sua permanência durante o período de internação para manutenção do vínculo afetivo criança-família. Os dados empíricos foram coletados com mães de crianças hospitalizadas, que não estavam acompanhando a internação do seu filho, num hospital público em Cascavel - Paraná, utilizando-se entrevista semi-estruturada. A análise dos dados demonstrou que as mães reconhecem a importância em permanecer com seu filho num periodo de estresse como o da hospitalização, porém, os fatores externos que influenciam seu cotidiano, muitas vezes não permitem que exerçam sua vontade de ficar com seus filhos.

UNITERMOS: hospitalização, vínculo afetivo criança-família

\section{APRESENTAÇÃO}

Este trabalho surgiu das reflexões cotidianas de nossa prática profissional, onde nos preocupamos com a assistência de enfermagem à criança hospitalizada e contempla questões surgidas no desenvolvimento do modelo de atenção centrado na criança e em sua família, interagindo com o meio ambiente em que cresce e se desenvolve, como tentativa de transformação da realidade da hospitalização infantil, uma vez que a criança não deve ser considerada como um ser isolado, mas um indivíduo posicionado em uma estrutura, a família, que se caracteriza por um relacionamento interdependente entre seus membros. O enfermeiro que opta pelo "cuidar de crianças" deve buscar a compreensão do fenômeno "relacionamento pais-filhos", apoiando, protegendo e fortalecendo o relacionamento dos pais com a criança durante a hospitalização, uma vez que a sua presença concorrerá para a efetivação do clima emocional desejável para a criança doente.

Pontuamos o significado do vínculo afetivo com sua família para que possa desenvolver-se com o mínimo possível de seqüelas emocionais, e ressaltamos os danos causados psicologicamente com a ruptura desse vínculo pela hospitalização, mesmo que temporariamente. Posteriormente detalhamos a metodologia utilizada e os resultados da análise dos dados coletados, apresentados a partir de três indicadores: a não permanência das mães durante a internação dos filhos, a mudança no cotidiano causada pela internação, a importância em permanecer com o filho internado e seu significado para a criança.

Temos como pressupostos, neste trabalho, que a mãe está se deixando influenciar por outros problemas externos à doença de seu filho, deixando-o só, durante a hospitalização; que os problemas sociais que vivencia dificultam a sua permanência no hospital; que a sua percepção sobre o alojamento conjunto pediátrico não está fortalecida pela compreensão da indissolubilidade do binômio mãe-filho; que a influência que o período de internação causa na vida da família afeta o convívio entre seus membros; que a equipe de saúde exige da mãe sua permanência na hospitalização, independente de fatores impeditivos.

Para tanto, nosso objetivo é verificar a percepção

\footnotetext{
* Trabalho de monografia apresentado como requisito para avaliação no Curso de Especialização de Enfermagem em Saúde Pública da UNIOESTE, em dezembro de 1997, orientado por Neusa Collet e apresentado no VI Colóquio Panamericano de Investigação em Enfermagem realizado em Ribeirão Preto - São Paulo, de 19 a 22 de maio de 1998

** Enfermeira, docente da disciplina de Enfermagem Materno Infantil II (Pediatria) do Departamento de Enfermagem da Universidade Estadual do Oeste do Paraná - UNIOESTE, especialista em Enfermagem do Trabalho e em Enfermagem em Saúde Pública, mestranda em Enfermagem Fundamental na Escola de Enfermagem de Ribeirão Preto da Universidade de São Paulo *** Enfermeira, docente da disciplina de Enfermagem Materno Infantil II (Pediatria) do Departamento de Enfermagem da Universidade Estadual do Oeste do Paraná - UNIOESTE, mestre em Enfermagem Fundamental, doutoranda no Programa Interunidades de Doutoramento em Enfermagem na Escola de Enfermagem de Ribeirão Preto da Universidade de São Paulo
} 
da mãe que tem o seu filho doente e hospitalizado, sobre a importância de sua permanência durante o período de internação para manutenção do vínculo afetivo criançafamília.

A intenção deste trabalho é rever o pressuposto da vinculação original, que acredita que o simples fato de proporcionar condições à mãe para que acompanhe seu filho durante a internação seja suficiente para que essa experiência se torne realidade.

\section{1 - A CRIANCA, A FAMÍlIA E A HOSPITALIZAÇÃO}

Nos primeiros anos de vida, a criança depende das ligações familiares para crescer. Ela carece de cuidados com o corpo, com a alimentação e com a aprendizagem. Mas nada disso é possível se ela não encontrar um ambiente de acolhimento e afeto. Os bebês não sobrevivem ao desamor. BOWLBY (1993) dizia que o amor materno, na infância e juventude, é tão importante para a saúde mental quanto as vitaminas e proteínas são para a saúde física.

A ligação afetiva entre a criança e sua família, e mais objetivamente com a mãe, é imprescíndivel para assegurar que as bases de formação psicológica do futuro adulto sejam mantidas intactas. A criança pode encontrarse em situação de privação do convívio familiar por diferentes motivos, sendo um deles a hospitalização.

Para Freud apud BOWLBY (1993), a situação que se deve evitar a todo custo não é tanto a da perda afetiva, mas a do intenso traumatismo do ego provocado pela perda. A situação traumática a ser evitada é a ruptura do estado emocional do indivíduo. No caso da criança, a causa de insegurança é, acima de tudo, a ausência da mãe (ou de substituto) ou a separação da mãe no momento em que a criança mais necessita de cuidado e proteção.

SPITZ (1979) ao abordar as doenças de carência afetiva do bebê, descreve duas situações resultantes desta privação: a privação afetiva parcial e a privação afetiva total ou hospitalismo.

Compreendendo a complexidade da criança e os reflexos que sua vivência terá para a vida adulta, temos um ponto de partida para a compreensão das forças e condições que fazem do homem um ser social. Nesta constelação de forças e condições, os afetos e trocas afetivas passam a ter um significado central. A capacidade do ser humano para estabelecer relações sociais é iniciada e adquirida na relação mãe-filho. É desse relacionamento que se estabelece o modelo para todas as relações humanas posteriores.

É no familiar significativo que a criança busca apoio, orientação, referências de tempo, proteção para o desconhecido e para o sofrimento. Se a criança pode contar com a assistência desse familiar, poderá ser mais capaz de suportar os sofrimentos e ansiedades surgidos durante a doença e a hospitalização. Quando os hospitais limitam a presença dos pais junto ao filho, tomam-lhes a responsabilidade do cuidado da criança e interferem no senso de confiança, satisfação e alívio que os pais obtêm, se bem sucedidos no atendimento das necessidades físicas, afetivas e até terapêuticas do filho doente (Bakwin apud SCHMITZ, 1989).

As bases da assistência à criança hospitalizada têm se modificado nas últimas décadas em decorrência dos resultados de pesquisas nas áreas das ciências médicas, humanas e sociais. A partir dessas contribuições desenvolveram-se diferentes perspectivas de como assistir a criança no processo saúde-doença e que vêm orientando a prática pediátrica. Essas perspectivas influenciam a visão dos profissionais sobre o ser criança, o papel da família e da comunidade, tipos de problemas a serem identificados, objetivos, a abrangência da assistência, a composição e inter-relacionamento da equipe de saúde. Todo o hospital dispõe de uma abordagem de assistência à criança hospitalizada que, mesmo não estando explicitada em suas normatizações, pode ser facilmente identificada pela observação.

As normas hospitalares rígidas e inflexíveis que se baseavam apenas na questão da contaminação do ambiente hospitalar, numa ótica microbiológica das causas das doenças, foram se modificando com o passar do tempo, pois foi sendo demonstrado que os germes hospitalares eram muito mais agressivos do que os germes que provinham do ambiente domiciliar do paciente e seus familiares. Paralelamente, a psicologia avançou, no entendimento dos distúrbios da criança, evidenciando que o distanciamento ou ausência dos pais em épocas importantes da vida da criança, participavam da gênese desses distúrbios, fossem eles precoces ou tardios.

Com a Constituição de 1988, o Brasil avançou na humanização do conceito de criança, com a promulgação do Estatuto da Criança e do Adolescente, que entre outros aspectos, garante o direito à saúde e à internação hospitalar com o acompanhamento dos familiares. Em 13 de julho de 1990, acompanhando o movimento nacional de democratização e participação da sociedade, foi promulgada a Lei ${ }^{\circ} 8.069$ que dispõe sobre o Estatuto da Criança e do Adolescente. No capítulo $\mathrm{I}$, trata do Direito à Vida e à Saúde, assegurando, ainda que no plano ideal, a proteção à criança e ao adolescente através de políticas sociais públicas, permita o desenvolvimento sadio e harmonioso em condições dignas de existência. No artigo 12, coloca que

"os estabelecimentos de atendimento à saúde deverão proporcionar condições para a permanência em tempo integral de um dos 
pais ou responsável, nos casos de internação de criança ou adolescente" (BRASIL, 1990, p.8).

Quando o hospital não permite a presença das mães permanentemente, descumprindo a legislação, impossibilita a mãe de acompanhar seu filho e cria um problema social e afetivo para a criança e a sociedade, uma vez que a ausência da mãe rompe o contato afetivo que dá segurança à criança que, futuramente, poderá vir a ser o adulto desequilibrado emocional e socialmente que tanto incomoda a sociedade de hoje.

\section{2 - CAMINHO METODOLÓGICO}

A coleta dos dados empíricos foi realizada em um hospital público estadual no município de Cascavel, Oeste do Paraná, cujo modelo de assistência à saúde é biologicista e hospitalocêntrico, centrado na figura do médico, na unidade de pediatria que atende crianças pelo Sistema Único de Saúde (SUS) com 32 leitos de internação. Esta unidade assegura o direito da mãe ou acompanhante em permanecer com a criança durante o período de hospitalização. A equipe de enfermagem é constituída por dois enfermeiros e vinte e sete auxiliares de enfermagem, divididos entre os cinco turnos de funcionamento $* * * *$.

Como nosso objetivo é apreender a compreensão das mães, sobre a importância de permanecer ao lado do filho durante a hospitalização, foi nesta instituição que realizamos a coleta dos dados. O projeto de pesquisa foi encaminhado à direção da instituição e do serviço de enfermagem, bem como a equipe da unidade, tendo sido aprovado. $\mathrm{O}$ mesmo não foi submetido a um comitê de ética devido a inexistência deste na referida instituição. A amostragem foi dada pelas mães que não estavam acompanhando seus filhos na unidade de alojamento conjunto, no período da coleta dos dados, a saber, no mês de setembro de 1997. Neste período, o número de crianças internadas sem a presença da mãe era de sete, destas houve possibilidade de entrevistar apenas quatro, uma vez que, dentre as demais, uma morava em outra cidade, impossibilitando o contato em função da distância, outra estava internada num hospital psiquiátrico e a terceira havia abandonado a criança aos cuidados de sua família.

O levantamento de dados junto às mães foi realizado por meio de entrevistas semi-estruturadas, as quais foram gravadas, com a autorização das entrevistadas e posteriormente transcritas.

Para a coleta de dados, formulamos questões norteadoras que servirão de fio condutor para a apreensão da realidade, a saber: Qual o motivo da sua não permanência com seu filho(a) no hospital, durante a hospitalização? Qual a sua percepção sobre a influência para seu filho(a) de sua ausência durante a hospitalização? Após o internamento de seu filho(a) houve mudança no vosso relacionamento, e com a família? Se mudou, em que aspectos? A Senhora acha importante ficar com seu filho(a) durante a internação?

Segundo MINAYO (1995), a pesquisa qualitativa não se preocupa em quantificar, mas sim, em compreender e explicar a dinâmica das relações sociais que, por sua vez, são depositários de crenças, valores, atitudes e hábitos. Trabalha com a vivência, com a experiência, com a cotidianeidade e também com a compreensão das estruturas e instituições como resultados da ação humana objetivada. A realidade recortada, por sua constante transformação é mais rica do que o olhar do pesquisador possa apreender.

O processo de análise foi desenvolvido a partir dos aspectos identificados em cada entrevista separadamente e, posteriormente, realizamos uma síntese de cada um, abordando a totalidade de aspectos que se apresentaram nas respostas. Esta síntese possibilitou uma análise sistemática de todas as questões norteadoras da entrevista em conjunto.

A classificação, por si só, não esgota a análise, é preciso ultrapassar os dados, tentando estabelecer relações que possibilitem novas explicações e interpretações, num indo e vindo que acompanhe as transformações do dado imediato, com o caráter histórico e social que o determina.

\section{3 - ANÁLISE E INTERPRETAÇÃO DOS DADOS}

Conforme pontuamos anteriormente, buscamos compreender o que está levando as mães do campo em estudo a não permanecerem com seus filhos durante o período de hospitalização, sinalizando como fatores responsáveis por esta conduta, problemas externos, problemas sociais, falta de compreensão da indissolubilidade do binômio mãe-filho e a mudança no cotidiano que a hospitalização causa.

\footnotetext{
**** A Instituição tem cinco turnos de funcionamento em função do horário noturno ser desenvolvido em jornadas de trabalho de 12 X60 horas, com carga horária de 36 horas semanais, desde janeiro de 1997
} 


\subsection{A não permanência das mães na internação dos} filhos

Com o início do projeto "alojamento conjunto pediátrico" a expectativa da equipe era de que, com apenas algum tempo de funcionamento, todas as mães das crianças que necessitassem de internamento hospitalar ficassem acompanhando seus filhos. Para surpresa dos profissionais da unidade, havia sempre um número "mais ou menos" determinado de crianças que permaneciam sozinhas durante a hospitalização. Essas crianças despertaram o interesse, pois passou a ficar evidente o contraste entre o modelo centrado na doença e o modelo de assistência integral, incluindo a família e os aspectos sociais do paciente na sua assistência.

No decorrer deste trabalho pontuamos alguns fatores que podem ou não determinar a uma mãe a sua permanência ou afastamento de seu filho num momento de crise como é a hospitalização. Esses fatores podem ser considerados externos, como a estrutura familiar, a existência de outros dependentes além da criança hospitalizada, a sua inserção no meio social em que vive, as atividades cotidianas que desempenha. A equipe de saúde tende a considerar que a mãe opta por não permanecer com seu filho na hospitalização, pré-julgando um desinteresse desta, pela criança que está deixando só no hospital. Não há o hábito de indagar quais são os seus impedimentos em relação ao filho que fica hospitalizado ou planejar com ela uma sistemática que permita a sua permanência, o máximo de tempo que dispuser. Apenas as regras rígidas da Instituição tem que ser cumpridas, com o objetivo de seguir uma normatização para racionalização do tempo e eficiência da assistência.

$\mathrm{Na}$ institucionalização da criança a lógica da instituição é geralmente normativa, burocratizante e centralizadora, enquanto que a criança e a família enfrentam um corpo biológico doente que comporta as dimensões emocional, subjetiva e de relações sociais, tentando manter seu ritmo de vida mesmo com os limites impostos pela hospitalização.

A hospitalização da criança é vista como uma situação crítica e delicada tanto para a criança e/ou família quanto para a equipe hospitalar. Durante a internação, vários fatores adversos estão presentes, como mudança do ambiente físico e psicológico, separação dos pais e demais familiares, interrupção das atividades cotidianas, entre outros. A hospitalização é uma das situações que envolve profunda adaptação do homem às várias mudanças que acontecem no seu dia-a-dia. Para responder a essa nova necessidade, os instrumentos e meios de trabalho também precisam alterar-se. A enfermagem precisa buscar nos referenciais sociais e psicológicos, subsídios para a reorganização da assistência, incluindo novas percepções sobre o meio onde a criança está inserida, buscando desenvolver ações que auxiliem no relacionamento da criança com a família, com a equipe, e com a família e equipe. As questões afetivas, psicológicas e emocionais também devem ter significado, pois fazem parte do processo de desenvolvimento infantil.

Assim, além da competência técnico-científica para atender às necessidades decorrentes do diagnóstico e terapêutica, a enfermeira necessita de instrumentos teóricos sobre crescimento e desenvolvimento e relações interpessoais que possibilitem compreender pais e filhos como pessoas. A formação do profissional enfermeiro se dá no sentido de que desenvolva sua prática profissional inserido numa equipe de saúde onde a ação de cada profissional forma o conjunto de atenção à saúde que a população necessita, ou seja, numa prática multi e interdisciplinar. Assim sendo, buscar auxílio nos referenciais da psicologia e outras ciências humanitárias não garante à equipe de enfermagem uma assistência à criança hospitalizada que envolva o contexto bio-psicosócio-cultural-ambiental-familiar. Para que essa assistência ocorra é importante a participação de outros profissionais, tais como médico, assistente social, psicólogo, nutricionista, fonoaudióloga, além do enfermeiro, possibilitando a complementariedade de ações que resultem em eficácia e eficiência na prestação de cuidados físicos e psicológicos à criança na unidade de alojamento conjunto pediátrico.

Neste sentido, além de rever a postura da equipe com as crianças que permanecem sem o acompanhamento da mãe, a enfermagem necessita uma abordagem diferenciada no trato com a família da criança, com enfoque para a comunicação, onde a importância vem do conhecimento e compreensão da criança na sua situação física, social e cultural, onde está inserida, tendo presente a subjetividade.

A comunicação com a criança/família, abrange o estudo da situação física, psíquica e social da criança/ família de forma a conhecer o seu comportamento. Para tanto, é necessário que os profissionais de enfermagem demostrem disponibilidade e atenção recíprocas e competências relacionais e de comunicação, tornandoas instrumentos essenciais na prática do cuidar.

O senso de cuidado e afetividade materna da mãe para com seu filho, fica bastante aparente em atenções básicas como a opção pela amamentação. Nas camadas menos favorecidas da população, como aquela que é atendida na instituição campo de estudo, a orientação de amamentação é realizada com enfoque de importância vital para o crescimento e desenvolvimento das crianças, porém, no caso específico em estudo, aparece como fator impeditivo para permanência da mãe no tratamento hospitalar de seu filho.

A mãe é a primeira pessoa de quem a criança depende para a satisfação de suas necessidades, assim 
podemos avaliar a importância que tem para a criança a natureza do vínculo que estabelece com a mãe, e a dificuldade de uma mãe ao ter que abrir mão, mesmo que temporariamente, deste vínculo, por menos culta ou informada que seja. Assim, os dados empíricos estão negando o pressuposto pontuado anteriormente de que a percepção da mãe sobre o alojamento conjunto pediátrico não está fortalecida da compreensão da indissolubilidade do binômio mãe-filho, pois além do instinto maternal natural, há o apego da relação de convivência que tem com seu filho, formado desde a gestação.

Quando formamos uma opinião a respeito de determinada conduta das mães não estamos levando em consideração o papel da equipe de enfermagem em relação à família, especialmente à mãe, pois estamos desconsiderando as condições que a levam a tomar determinada conduta, tentando suplantar à família, quando deveríamos suplementá-la tendo como objetivo comum o bem-estar da criança.

\subsection{A mudança no cotidiano causada pela hospitalização}

Para apreendermos as mudanças no dia-a-dia familiar após a hospitalização de um de seus membros, estaremos contextualizando a família, pois com o modelo de assistência do campo de estudo da pesquisa, onde os trabalhadores de saúde desenvolvem uma prática baseada na participação dos pais, faz-se necessário compreender a dimensão social, na qual as famílias se inserem, com as demandas psíquicas e emocionais que os indivíduos formulam, a partir dos valores que atribuem às relações e às mudanças intensas e rápidas que ocorrem nestes valores, transformando o sentido e o significado das próprias relações.

Neste tópico, corroboramos o pressuposto de que a influência que o período de internação causa na vida da família afeta o convívio entre seus membros. De uma maneira geral, a doença surge inesperadamente e toma de assalto a família, principalmente quando o acometimento se dá com uma criança. Quando há necessidade de hospitalização, nem a família, nem a criança encontram-se preparadas para lidar com essa mudança repentina no cotidiano. Para a criança a hospitalização representa medo do desconhecido, sofrimento físico com os procedimentos e sofrimento psicológico relacionado a todos os sentimentos novos que passa a vivenciar. Para a família significa o sentimento de perda da normalidade, de insegurança na função de progenitores, de alteração financeira no orçamento doméstico, de dor pelo sofrimento do filho. A literatura especializada justifica que a criança e a família necessitam de esclarecimentos, informações e orientações, contudo, não é o que observamos ocorrer em nossa prática profissional. Em decorrência disso, no cotidiano hospitalar, deparamo-nos com uma série de situações conflituosas entre a família e a equipe de saúde, que poderiam ser evitadas.

A perda da normalidade pode ser evidenciada pela ausência da criança em casa, significando que estará deixando uma lacuna nas atividades dos demais membros da família, quando sobrar um lugar à mesa, quando não precisar levá-lo à escola, quando não houver necessidade de recolhê-lo das brincadeiras com irmãos e amigos, ou ainda de intervir nas suas atitudes para corrigir desvios e estimular uma conduta coerente com a vivência e a crença da família.

Há ainda o caso dos trabalhadores informais, que não estão amparados legalmente para resguardar o emprego caso tenham que se ausentar para cuidar dos filhos doentes, e que geralmente são demitidos de seus trabalhos quando isso ocorre. Há horários estabelecidos também para troca dos familiares que estão acompanhando a criança, ou para a entrada daquelas mães que não permanecem todo o tempo com o filho. Porém, ocorre inflexibilidade também nesses horários, o que causa transtornos para a família e a criança.

A mudança de vida para a família, especialmente para a mãe, que acumula as atividades de educadora dos filhos, dona de casa e, na maioria das vezes, com emprego fora de casa, ocorre em todos os níveis, fazendo com que as mães tenham que dar conta de lidar com todos os aspectos modificados, além do estresse vivenciado com a doença da criança.

\subsection{A importância em permanecer com o filho internado e seu significado para a criança}

Para garantir a manutenção do vínculo mãecriança, os hospitais voltados para a formação dos profissionais da área de saúde, têm mostrado interesse no envolvimento da família quando se trata da internação de crianças. Uma estratégia que está sendo utilizada, é a participação dos pais através da elaboração de projetos, como o existente no campo de estudo desta pesquisa, programas de pais participantes, mãe acompanhante, ou outros. Esses programas são fundamentais, em nossa opinião, para prestar uma assistência mais abrangente à criança, denominada na enfermagem como assistência integral à criança.

Segundo COLLET \& ROCHA (1996), essa noção de integralidade está relacionada à não fragmentação do cuidado em tarefas, à participação da mãe neste cuidado, à interação com a mãe e a criança através do brinquedo facilitando a comunicação com ambos. A assistência integral compreende um trabalho interdisciplinar de parceria sem eliminar a competência técnica profissional dos agentes envolvidos no cuidado. 
A interdependência do cuidado construído no cotidiano, também estabelece uma relação de cooperação envolvendo a equipe de saúde, a criança e a família.

A criança hospitalizada, em nosso contexto, tem seu corpo biológico doente em evidência, precisando que a equipe de enfermagem proporcione cuidados de alimentação, higiene, conforto, segurança, medicação, carinho, entre outros. Quando a mãe está presente para proporcionar a atenção às necessidades afetivas, o serviço de enfermagem tem uma aliada no desenvolvimento da assistência integral, contudo, na ausência da mãe, este mesmo serviço deve incorporar a assistência emocional à criança, de modo a garantir a continuidade no recebimento da afetividade.

A mãe que permanece com seu filho no hospital necessita de acompanhamento do serviço de enfermagem e dos demais profissionais de saúde da unidade, uma vez que o seu estado psicológico também está abalado em função da doença. A mãe que não pode permanecer carece de um cuidado igual ou maior ao daquele recebido pelas outras mães, pois está desamparada em relação à doença de sua criança. Não acompanha de perto o tratamento, não conhece as necessidades que o seu filho está passando, fantasia sobre os cuidados ou "descuidados" que a criança está recebendo, não tem o mesmo nível de informação sobre a evolução da assistência que as outras mães, além de sentir uma cobrança maior da equipe de enfermagem pelo fato de não permanecer acompanhando a hospitalização do seu filho.

Quando perguntado às mães sobre a importância de sua permanência na hospitalização do filho, todas, sem exceção, salientaram a necessidade de permanecer junto ao filho, porém, em função dos aspectos pontuados até agora, não houve possibilidade de opção a essas mães, mas sim a imposição de sua inserção na sociedade, refletida nos aspectos impeditivos que as obrigaram a "abandonar" suas crianças no hospital.

Independente da idade, mudanças repentinas no cotidiano da criança, como a hospitalização, exercem influências sobre o estado emocional, afetivo e de relacionamento. Mesmo após a primeira infância, a presença da mãe é importante, como demonstra SPITZ (1979) que não restringe a importância do vínculo materno apenas aos primeiros três anos de vida e argumenta que após esta idade ele modifica suas formas de expressão.

Os profissionais de saúde parecem, em algumas situações, não perceber que na ausência da mãe a criança requer mais atenção, carinho e proximidade. Quando a mãe está presente, é ela em geral, que proporciona este tipo de afeto e hoje, pela presença quase que constante das mães em nossa realidade, eles deixaram em segundo plano este cuidado que também é seu. Ocorre ainda a falta de sensibilidade da equipe para perceber que essas necessidades da criança tornam-se mais agudas quando ela não recebe a visita da mãe diariamente.

Outro aspecto percebido na fala de uma das mães é a questão contraditória da compensação psicológica que faz por estar ausente numa situação de crise, quando compensa a dor do afastamento pela noção da satisfação das necessidades físicas da criança.

Com os aspectos abordados até então, não conseguimos convalidar o pressuposto de que a percepção da mãe sobre o alojamento conjunto pediátrico não está fortalecida da compreensão da indissolubilidade do binômio mãe-filho. Apesar da precariedade de conhecimentos das entrevistadas, avaliada pelo nível de escolaridade e condições de acesso a informações, além das condições sócio-econômicas, se fosse oferecido a essas mães meios que oportunizassem a sua permanência durante a hospitalização, todas elas estariam acompanhando suas crianças, conforme ficou aparente em suas falas. Independente do direito de permanência ser assegurado por meio do "projeto alojamento conjunto pediátrico" a ausência das mães pode estar sendo determinada pelas questões impeditivas pontuadas até o momento.

Ao introduzirmos este tópico, lembramos que a participação da mãe ou outro familiar, independente do modelo que propicie esta interação, é de extrema importância para a assistência integral da criança doente. Pela fala das mães percebemos que todas consideram importante permanecer com seus filhos. Em função disso, surge a questão de como viabilizar socialmente que essa permanência ocorra. Parece-nos que foge ao alcance da enfermagem ou da equipe multiprofissional viabilizar uma mudança nesse contexto isoladamente. Porém, independente disso, os profissionais de saúde podem assumir o compromisso de tentar suprir a carência psicológica da criança e da mãe devido ao rompimento temporário do vínculo que os une. $\mathrm{O}$ estabelecimento de vínculo também pode ocorrer entre a criança e a equipe de saúde. Pela vivência no hospital a criança passa a conhecer os trabalhadores e a manter um relacionamento afetivo e carinhoso com os mesmos, se houver abertura da equipe para isso.

Concordamos com LIMA (1996), quando coloca que, ao se estabelecer o vínculo pressupõe-se o estabelecimento da responsabilidade, não individual, mas do binômio serviço de saúde/profissionais e paciente/ família. Esta é outra "tarefa" que não é fácil mas a aposta na construção de um futuro mais solidário, fraterno e esperançoso nos impulsiona a transpor barreiras, pois o que está em jogo não é apenas o prolongamento da vida das crianças, mas, também, a melhora de sua qualidade de vida.

Acreditamos que além do cuidado com o corpo biológico, a criança hospitalizada tem outras 
necessidades, percebidas através da vivência profissional e da análise dos dados desta pesquisa, como formação e manutenção dos vínculos (na percepção de suas mães), dispor de lazer, contar com a companhia da mãe durante a internação ou nos horários de visita, brincar, receber afeto, amar e ser amada, seja pela família ou pela equipe de saúde.

\section{CONSIDERAÇÕES FINAIS}

Iniciamos esta investigação com o objetivo de verificar a percepção da mãe que tem o seu filho doente e hospitalizado, sobre a importância de sua permanência durante o período de internação para manutenção do vínculo afetivo criança-família. A partir da confrontação dos dados e análise apresentados anteriormente, temos subsídios para afirmar que a mãe, apesar de seu saber "senso comum", tem presente a ligação com seu filho como fator de relevante importância para o seu desenvolvimento. Na sua percepção, a criança sente sua ausência e pode sofrer perturbações decorrentes do período em que estão separados.

A mãe percebe como importante a assistência emocional que o filho precisa, que normalmente seria ofertada por ela e que temporariamente está abstendo-se desta função. Contudo, percebe sua limitação em relação aos cuidados profissionais que a criança necessita para curar-se da doença adquirida, surgindo a ambivalência entre o que sente e o que o filho precisa para "ficar bom". Apesar da culpa por estar deixando o filho aos cuidados de outras pessoas, a mãe acredita que a equipe de enfermagem estará prestando toda assistência às necessidades de sua criança.

Nesta perspectiva, pontuamos como necessidade premente que o serviço de enfermagem e a equipe de saúde que prestam assistência à criança hospitalizada, com todo o seu processo de trabalho, voltem sua atenção para o preenchimento das necessidades afetivas da criança. É importante tentar criar com ela um vínculo que dê condições ao bem-estar físico e emocional, saindo do modelo biologicista para a assistência integral, uma vez que, conforme destacado neste trabalho, estaremos sempre lidando com situações impeditivas às mães, fazendo com que um determinado número de crianças fiquem hospitalizadas sem o seu acompanhamento e, portanto, carentes do seu afeto, carinho e atenção.

Parece-nos oportuno destacar que a equipe de saúde do "alojamento conjunto pediátrico" expanda suas atenções aos aspectos psicológicos da hospitalização infantil, principalmente nos casos em que houver separação do binômio mãe-filho e empreenda esforços para melhorar sua prática profissional, a qual precisa estar fundamentada em princípios científicos e sobretudo em ações práticas, através de um relacionamento terapêutico que, além de atender as necessidades técnicas do cuidado, esteja voltado também para o atendimento das necessidades emocionais da criança que está sob os seus cuidados.

Outro aspecto importante a ser pontuado neste momento, é o impacto que a hospitalização de uma criança causa na vida da família, desestruturando-a e fazendo com que seus membros tenham de passar por uma modificação temporária, adaptando-se ou não a nova situação estressora criada involuntariamente pela doença.

Ao internar seu filho, os pais estão se expondo. Normalmente, a sociedade e a própria mãe crêem que a responsabilidade do cuidado da criança deva ser seu e que ela deva ser um modelo de sacrifício e devoção. Assim, com o evento da doença, surge o sentimento de falha em relação à maternidade, que pode determinar sentimento de culpa, presente nas falas de nossas entrevistadas, confusão, inadequação e infelicidade.

No hospital os pais podem ter dificuldade de saber como agir para atender às necessidades físico-psico emocionais de seu filho, que está doente e num ambiente que tem situações e regras próprias. A indecisão, a insegurança e a ansiedade levam os pais a mudar de comportamento, o que é percebido pela criança, que busca sua segurança no padrão de cuidados ao qual está acostumada. Ora, o papel que os pais desempenham é vital para o ajustamento social e psicológico da criança durante a hospitalização, seja qual for a sua idade.

Normalmente, a atenção da equipe assistencial hospitalar se volta para a criança. As necessidades e problemas da família são esquecidas ou tem atenção secundária, a despeito do fato de que a relação dos pais e filhos define e dirige o nível de tensão emocional da criança.

Desta forma, tornamos a ressaltar que, trabalhar com crianças significa trabalhar também com seus pais, especialmente com sentimentos e atitudes.

Apontamos também como fator relevante para a discussão, o comportamento da equipe de enfermagem frente à impossibilidade da mãe em permanecer com o filho no hospital, geralmente de insensibilidade pelos seus problemas. Muito pouco se lembra que a criança/paciente não é do hospital. Mesmo com cuidados excelentes da equipe de saúde a cura dos problemas biológicos por si só não basta, enquanto não se previnem os distúrbios psíquicos e deficits intelectuais nas crianças hospitalizadas, não conseguiremos atingir o objetivo da assistência integral. 
HOSPITALIZED CHILDREN: MOTHERS' PERCEPTION ABOUT THE AFFECTIVE CHILDFAMILY LINK

This purpose of this research was to verify the perception of the mother who has her child sick and hospitalized, about the importance of her permanence during the hospitalization time for the maintenance of the affective child-family link. Empiric data were collected with mother's of hospitalized children, who were accompanying the hospitalization of their children in a public hospital at the Cascavel city in the West of Paraná, Brazil, through semi-structured interviews. The analysis of these data demonstrated that the mothers recognize the importance of staying with their children in such a stress time like the hospitalization time, however, the external facts that influence their daily life, often do not allow them to stay with their children.

KEY WORDS: hospitalization, the affective child-family link

\section{NIÑO HOSPITALIZADO: EL VINCULO AFECTIVO NIÑO-FAMÍLIA}

Este trabajo tiene como objetivo verificar la percepción de la madre que tiene su hijo enfermo hospitalizado, sobre la importancia de su permanencia durante el periodo de internación para la manutención del vinculo afectivo del niño-familia. Los dados empiricos fueron colectados con madres de niños hospitalizados, que no estaban acompañando la internación de su hijo, en un hospital publico en Cascavel - Paraná, utilizase una entrevista semi-estructurada. El análisis de los datos demostró que las madres reconocen la importancia en permanecer con su hijo en un periodo de estrés como de la hospitalización, sin embargo, los factores externos que influencian su cotidiano, muchas veces no permiten que ejerzan su voluntad de quedar con sus hijos.

TÉRMINOS CLAVES: hospitalización, el vinculo afectivo del niño-família

\section{REFERÊNCIAS BIBLIOGRÁFICAS}

01. BOWLBY, J. Angústia e separação : revisão da literatura. In: Separação: angústia e raiva.

2. ed. São Paulo: Martins Fontes, 1993. Apêndice 1, p. 389-411.

02. BRASIL. Ministério da Saúde. Estatuto da criança e do adolescente. Brasília: Ministério da Saúde, 1990. $110 \mathrm{p}$.

03. COLLET, N.; ROCHA, S.M.M. Transformações no ensino das técnicas em enfermagem pediátrica. Goiânia: AB Editora, 1996. 146 p.
04. LIMA, R.A.G. Criança hospitalizada: a construção da assistência integral. Ribeirão Preto, 1996. Tese (Doutorado) - Escola de Enfermagem de Ribeirão Preto e São Paulo, Universidade de São Paulo.

05. MINAYO, M.C.S. et al. Pesquisa social: teoria, método e criatividade. 4.ed. Petrópolis: Vozes, 1995. $80 \mathrm{p}$.

06. SCHMITZ, E.M. et al. A enfermagem em pediatria e puericultura. Rio de Janeiro: Atheneu, 1989. $477 \mathrm{p}$

07. SPITZ, R.A. Doenças de carência afetiva do bebê. In: O primeiro ano de vida. 7. ed. São Paulo: Martins Fontes, 1979. cap. 14, p. 119-212. 